\section{HP0004 HAND'S REHABILITATION IN RHEUMATOID ARTHRITIS}

${ }^{1} \mathrm{JD}$ Petit, ${ }^{1}$ RC Camp, ${ }^{2}$ AR De la Serna. 'Physiotherapy; ${ }^{2}$ Rheumatology, Sant Pau, Barcelona, Spain

\subsection{6/annrheumdis-2001.1244}

Objective Decrease of pain and inflammation, maintenance articular mobility, muscular power and prevention of tendons rupture.

Material We conducted a prospective study in 530 rheumatoid arthritis female patients suffering from bilateral hand sinovitis with an average of 45 years old (range 25-69 years old).

Method The following treatment was used during 2-3 sessions/ week for six months.

Acute phase: cryotherapy and rest with orthesis in functional position.

Chronic phase: thermotherapy; paraffin bath and passive and active exercise alternating with rest; ring orthesis; articular saveness and healthy education.

We have measured the results through followings items:

Pain: visual analogic scalee (VAS)

Hand grip strength: $\mathrm{mm}$. $\mathrm{Hg}$

Functional capacity: health assessment questionary (HAQ) Results Table 1.

\begin{tabular}{llll}
\multicolumn{4}{l}{ Abstract HP0004 Table 1} \\
\hline & Baseline & 1 month & 6 month \\
\hline Pain & $7 / 8$ & $5 / 6$ & $3 / 4$ \\
Grip strength & $30 / 40$ & $40 / 50$ & $40 / 60$ \\
Functional capacity & $1,5 / 2$ & $0,9 / 1,2$ & $0,5 / 0,8$ \\
\hline
\end{tabular}

Conclusions Rheumatoid arthritis hand's physiotherapy increase quality of life and articular movility, and decrease of pain. This treatment in not able to stop the progression of the illness.

\section{HP0005 EXPECTATIONS OF RA-PATIENTS, RHEUMATOLOGISTS AND PHYSIOTHERAPISTS ABOUT THE OUTCOME OF HIGH INTENSITY EXERCISE PROGRAMS IN COMPARISON WITH CONVENTIONAL EXERCISE PROGRAMS}

${ }^{1} \mathrm{M}$ Munneke, ${ }^{2} \mathrm{Z}$ De Jong, ${ }^{3} \mathrm{HK}$ Ronday, ${ }^{4} \mathrm{CH}$ Van den Ende, ${ }^{2} \mathrm{TP}$ Vliet Vlieland, ${ }^{5} \mathrm{JM}$ Hazes. 'Physical Therapy; ${ }^{2}$ Rheumatology, University Hospital, Leiden, The Netherlands; ${ }^{3}$ Rheumatology, Hospital Leyenburg, The Haque, The Netherlands; ${ }^{4}$ Nivel, Utrecht, The Netherlands; ${ }^{5}$ Rheumatology, University Hospital, Leiden/Rotterdam, The Netherlands

\subsection{6/annrheumdis-2001.1245}

Results of recent studies indicate that high intensity exercise programs may be beneficial for patients with RA. Beliefs about the outcomes of high intensity exercise will influence the willingness of rheumatologists and physiotherapists (PT's) to refer patients for participation in high intensity exercise programs and the willingness of RA patients themselves to participate in such programs. The aim of this study was to examine the expectations of rheumatologists, PT's and RA-patients with respect to the outcome of high intensity exercise in comparison with conventional exercise.

Methods A self-developed exercise beliefs questionnaire was administered to 153 rheumatologists, 624 PT's and 807 RApatients who were eligible for participation in a multicenter, randomised controlled trial on the effect of a long-term intensive exercise programme. The questionnaire comprised two questions about negative outcome expectations (exercise results in joint damage and exercise results in an increase of disease activity) and two questions about positive outcome expectations (exercise is beneficial, exercise results in an increase in physical fitness) for both high intensity exercise and conventional exercise separately. Total scores for outcome expectations were calculated and ranged from very negative (-6) to very positive (6).

Results The response rates for rheumatologists, PT's and patients were $83 \%, 70 \%$ and $75 \%$. Only the results of PT's treating at least one RA-patient per week ( $\mathrm{n}=121,28 \%$ of responding PT's) are presented.

Conclusion Rheumatologists, PT's and RA-patients have more negative expectations about the outcome of high intensity exercise than about the outcome of conventional exercise. This finding may be a potential barrier for referral to or participation in high intensity exercise programs. Factors underlying the relatively negative attitude towards high intensity exercise, such as a lack of information and personal experiences with high intensity exercise, need to be further examined.

\begin{tabular}{|c|c|c|c|}
\hline \multicolumn{4}{|c|}{ Abstract HP0005 Table 1} \\
\hline & $\begin{array}{l}\text { Outcome } \\
\text { expectations high } \\
\text { intensity exercise } \\
\text { (median, range) }\end{array}$ & $\begin{array}{l}\text { Outcome } \\
\text { expectations } \\
\text { conventional } \\
\text { exercise (median, } \\
\text { range) }\end{array}$ & $\begin{array}{l}\text { p-value expectations } \\
\text { high intensity versus } \\
\text { conventional } \\
\text { exercise }\end{array}$ \\
\hline $\begin{array}{l}\text { Rheumatologists } \\
(n=123)\end{array}$ & $2(-2,6)^{*}$ & $3(0,6)^{*}$ & $P<0.001$ \\
\hline $\begin{array}{l}\text { Physiotherapists } \\
(n=121)\end{array}$ & $0(-6,5)^{*}$ & $3(-1,6)^{*}$ & $P<0.001$ \\
\hline $\begin{array}{l}\text { RA Patients ( } \mathrm{n}= \\
\text { 578) }\end{array}$ & $1(-6,6)^{*}$ & $2(-4,6)^{*}$ & $P<0.001$ \\
\hline
\end{tabular}

\section{HP0006 A RANDOMISED CONTROLLED TRIAL EVALUATING EFFECTIVENESS OF THREE HAND TREATMENT APPROACHES IN RHEUMATOID ARTHRITIS (RA)}

${ }^{1} \mathrm{AV}$ Chadwick, ${ }^{2} \mathrm{C}$ Simpson, ${ }^{2} \mathrm{~K}$ Murray, ${ }^{2} \mathrm{D}$ Mulherin, ${ }^{3} \mathrm{PW}$ Jones, ${ }^{1} \mathrm{~K}$ Dziedzic. ${ }^{1}$ Physiotherapy Studies; ${ }^{2}$ Rheumatology and Rehabilitation, Mid-Staffs General Hospitals Trust, Cannock, UK; ${ }^{3}$ Mathematics, Keele University, Keele, UK

\subsection{6/annrheumdis-2001.1246}

Background Little evidence available about optimum therapy for the rheumatoid hand or its effect on disability.

Objectives To evaluate the effectiveness of three different therapeutic approaches to the rheumatoid hand.

Methods 67 Subjects $(M=20)$, mean age 59.6 yrs (range 24-77 yrs) and disease duration 13.4 yrs (range 1-52 yrs), were randomised to 3 groups. Each subject received written and verbal information about joint protection from an experienced therapist. Group 1 subjects received strengthening and mobilising exercises, Group 2 stretching exercises and Group 3 the joint protection advice alone. Subjects in Groups 1 and 2 undertook a graduated programme of increasing repetitions (up to 20) of the exercises, twice daily over the six month study period. Outcome measures were obtained by two blinded assessors at 1, 3 and 6 months using AIMS II subscales relating to upper limb, hand 
and finger function; dynamometry; gross and pinch grip measured using the Jamar dynamometer; the Jebson-Taylor Hand Function Test and goniometry including joint ranges for wrist, thumb and individual fingers of each hand. Ethical approval was granted from the Local Research Ethics Committee.

Results 67 patients with a confirmed diagnosis of RA entered into the study. There were no statistically significant differences in baseline characteristics or demographic data. 52 patients completed all visits for all measurements. 58 attended at their one month measurement and 54 at their 3 month measurement. 15 subjects dropped out of the study. There was no significant difference in drop out rates between the 3 groups. One subject was lost to follow up. Analysis was performed using the SPSS package version 10.0. Differences in change between baseline and follow-up at 6 months were assessed using ANOVA for approximately normal data and Kruskal-Wallis test for non-normal data. At 6 months there was a statistically significant difference in AIMS II Upper limb function ( $p=0.007$, F-ratio 5.47) in the 3 groups. Comparison of pairs of groups at the 5\% level of significance with Bonferroni adjustment showed that Group 1 was significantly different from Groups 2 and 3. In addition there were non-significant differences but improvements noted in AIMS (hand and finger function subscales) and pinch grip for both hands in this group. There were no changes in hand function or impairment measures in Groups 2 or 3.

Conclusions This study demonstrates a statistically and clinically significant improvement in upper limb function following a programme of home strengthening hand exercises in patients with RA. Further work is recommended to evaluate which specific exercises are most beneficial.

\section{HP0007 THE HAQ INDEX - RELATIONS TO DIFFICULTY IN DAILY ACTIVITIES}

${ }^{1} \mathrm{KU}$ Nordh, ${ }^{2} \mathrm{U}$ Nordenskiöld. 'Department of Occupational Therapy, Division of Rheumatology, Karolinska Hospital, Stockholm, Sweden; ${ }^{2}$ Department of Occupational Therapy and Rehabilitation Medicine, Sahlgrenska Universitetssjukhuset, Gothenburg, sweden

\subsection{6/annrheumdis-2001.1247}

The objectives were to make an analysis of the HAQ disability index concerning if the patients marked their difficulty in the answere alternatives "no, any or much difficulty" and "using assistive devices" as well as if their assistive devices were in use at home.

The methods One hundred and eighteen patients, with rheumatoid arthritis have attended in the program "Early Arthritis" which all have been at their two year control at Karolinska hospital. One hundred and eighteen of 124 patients were included in this study, 30 male and 88 female with the mean age of 53 years. The patients have marked their perceived difficulty in the HAQ seven times during two years and filled in a checklist with assistive devices. In the HAQ the scale steps are $0=$ no difficulty, 1 = with any difficulty, 2 = with much difficulty, $2=$ with assistive devices and $3=$ unable to do. Both "much difficulty" and "using assistive devices" are scored with the scale step 2.

The results showed that 99 of 118 patients had assistive devices at home, 20 men had 4.6 assistive devices and 79 women had 10 assistive devices per person. In spite of that $97 \%$ of the devices were in use by the men and $95 \%$ were in use by the women, seventeen men and 57 women had never filled in the answere alternative "with assistive devices" in the HAQ, even though they were using the devices. If the men and the women had filled in the alternative "with assistive devices", an increased HAQ index should have been identified. The mean value had increased from 0,28 to 0,5 for the men and for the women the mean value had increased from 0,56 to 0,89 .

The conclusion The HAQ index is not reliable enough to show the level of patients perceived difficulty in daily activities in relation to using assistive devices. The scale step 2 is used for both "much difficulty" and for "with assistive devices" and the patients in this study had not filled in the alternative "with assistive devices". The HAQ index mixes two different aspects of disability, dependence in terms of use of assistive devices and perceived difficulty.

\section{REFERENCES}

1 Fries JF. The assessment of disability; from first to future principles. $\mathrm{Br} J$ Rheumatol. 1983; 22(3 Suppl):48-58

2 Guillemin F, Briacon S, Pourel J. Validity and discriminant ability of HAQ Functional Index in early rheumatoid arthritis. Disabil Rehabil.1992;14:71-7

3 Tennant A, Hillman M, Fear J. Are we making the most of The Stanford Health Assessment Questionnaire? Br J Rheumatol. 1996;35:574-8

4 Nordenskiöld U, Grimby G. Assessment of disability in women with rheumatoid arthritis in relation to grip force and pain. Disabil Rehabil. 1997;19:13-9

\section{HP0008 THE USE OF COMPLEMENTARY AND ALTERNATIVE MEDICINE IN PATIENTS WITH RHEUMATOID ARTHRITIS}

${ }^{1} \mathrm{AC}$ Seymour, ${ }^{1} \mathrm{CA}$ Mayes, ${ }^{1} \mathrm{KA}$ Young, ${ }^{2} \mathrm{~S}$ Stafford, ${ }^{3} \mathrm{~L}$ Waterhouse, ${ }^{4} \mathrm{H}$ Dart. ${ }^{1}$ Rheumatology, St Albans City Hospital, St Albans; ${ }^{2}$ Rheumatology, Winchester and Eastleigh, Winchester; ${ }^{3}$ Rheumatology, Selly Oaks, Birmingham; ${ }^{4}$ Rheumatology, Robert Jones and Agnus Hunt, Oswestry, UK

\subsection{6/annrheumdis-2001.1248}

Background There are few randomised-controlled studies on the efficacy of Complementary/Alternative Medicine (CAMs). Lack of or misleading information for patients could lead to inappropriate management. There is little liaison or accountability between medical and CAM practitioners in the UK and little information on referral patterns and extent of knowledge about CAMs amongst rheumatologists. For this reason there may be a need for a structured departmental policy.

Aims To assess the number, type and cost of CAMs used by patients with Rheumatoid Arthritis (RA).

Methods A postal questionnaire was sent to 200 patients who are still attending The Early Rheumatoid Arthritis Study (ERAS), a long term observational study of early RA from 9 different regions of England. The ERAS database holds details of all drug therapies and outcomes on patients for up to 13 years follow up. The responses of the first $100(\mathrm{n}=33 \mathrm{M}, 67 \mathrm{~F})$ patients are reported here.

Results 76 patients had used or were currently using CAMs (currently using $\mathrm{n}=35, \mathrm{n}=41$ have used). Reasons for their use were:- Symptom relief $(\mathrm{n}=30)$, GP advice $(\mathrm{n}=2)$, Rheumatologist advice $(\mathrm{n}=2)$, wanting to find alternatives to Rheumatology drugs $(n=26)$, other $(n=9)$ and not recorded $(n=4)$. The most widely used CAMs were:- vitamin supplements $(\mathrm{n}=$ $53,73 \%)$, Homeopathy $(\mathrm{n}=30,41 \%)$, copper bracelet $(\mathrm{n}=$ $31,42 \%)$, Acupuncture $(\mathrm{n}=33,45 \%)$, Osteopathy $(\mathrm{n}=$ $29,40 \%)$, Aromatherapy ( $\mathrm{n}=19,26 \%)$, cod liver oil $(\mathrm{n}=19$, $26 \%)$ and multivitamins $(n=17,23 \%) .54$ patients used more than one. Cost to each patient over the last year:- $<£ 15$ (n = 14), $£ 15-£ 50(\mathrm{n}=16), £ 50-£ 100(\mathrm{n}=6),>100(\mathrm{n}=8)$ and not recorded $(n=29)$. Of the 35 patients currently on CAMs, 22 